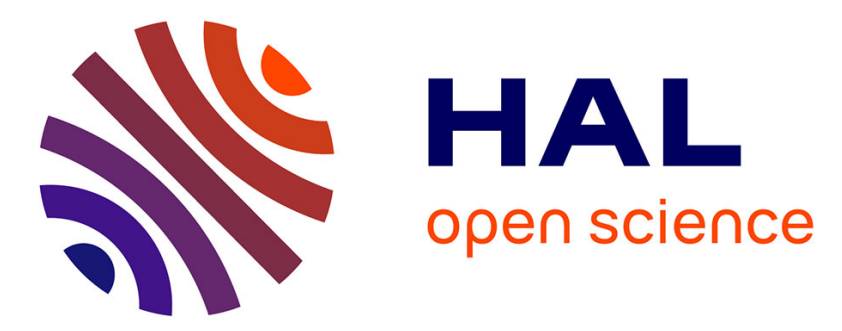

\title{
Interval force/position modeling and control of a microgripper composed of two collaborative piezoelectric actuators and its automation.
}

Sofiane Khadraoui, Micky Rakotondrabe, Philippe Lutz

\section{- To cite this version:}

Sofiane Khadraoui, Micky Rakotondrabe, Philippe Lutz. Interval force/position modeling and control of a microgripper composed of two collaborative piezoelectric actuators and its automation.. International Journal of Control, Automation and Systems, 2014, 12 (4), pp.358-371. hal-01303403

\section{HAL Id: hal-01303403 \\ https://hal.science/hal-01303403}

Submitted on 18 Apr 2016

HAL is a multi-disciplinary open access archive for the deposit and dissemination of scientific research documents, whether they are published or not. The documents may come from teaching and research institutions in France or abroad, or from public or private research centers.
L'archive ouverte pluridisciplinaire HAL, est destinée au dépôt et à la diffusion de documents scientifiques de niveau recherche, publiés ou non, émanant des établissements d'enseignement et de recherche français ou étrangers, des laboratoires publics ou privés. 


\title{
Interval force/position modeling and control of a microgripper composed of two collaborative piezoelectric actuators and its automation
}

\author{
Sofiane Khadraoui, Micky RaKotondrabe and Philippe Lutz
}

\begin{abstract}
This paper deals with the modeling and control of a microgripper devoted to micromanipulation and microassembly applications and tasks. Based on two collaborative piezoelectric actuators, the microgripper is typified by a high sensitivity to the environment, in particular a high sensitivity to the properties of the manipulated objects. This sensitivity makes the behavior of the microgripper variable and uncertain versus the environment and consequently makes the tasks lose performances. A possible way to overstep that problem is to model the microgripper behavior and its dependency with the environment as perfect as possible and then calculate a controller from this. However, such model is complex to handle and the yielded controllers are often very complex for implementation. In this paper, we propose to use interval models to describe the behavior of the piezoelectric actuators that compose the microgripper. Then a controllers synthesis consisting in combining interval techniques and classical control theory is proposed. Both the position and the force raised in the microgripper are considered. The main advantages of the proposed technique are: 1) ease and natural way to model the uncertainties, 2) the robustness of the synthesized controllers, 3) and the derivation of low order controllers that are easier for implementation relative to those of classical robust control techniques. Finally, the paper presents the application of the controlled microgripper to an automated pick-transport-and-place task of micro-objects. This automated task demonstrates the efficiency of the control technique in micromanipulation and microassembly applications.
\end{abstract}

Keywords: Collaborative piezoelectric actuators, Interval modeling and control, Force/Position signals, Robust controller, Parametric uncertainties, Microgrippers, Automated pick-and-place tasks.

\section{INTRODUCTION}

Pick-and-place tasks are common in micromanipulation, microassembly and micrograsping applications. A pick-and-place of small objects (objects having sizes less than one millimeter) generally includes three principal subtasks: grasping the object, moving it from its initial location to a desired one, and releasing it at this desired location. While micromanipulation and microassembly applications require a micrometric or submicrometric resolution and accuracy, the elementary pick and place operations should be performed with the same performances. To reach such severe accuracy, actuators fabricated on the basis of smart materials are often employed because of their capability to replace hinges by flexure techniques and consequently to highly improve the positioning resolution. In fact, mechanical clearances in hinges drastically decrease the resolution. Piezoelectric materials are one of the most appreciated smart materials thanks to their favorable properties: high bandwidth (more than the kiloHertz

Automatic Control and Micro-Mechatronic Systems Department, AS2M FEMTO-ST Institute, UMR CNRS 6174 / UFC / ENSMM / UTBM 24 rue Alain Savary, Besançon 25000, France. Corresponding author: mrakoton@femto-st.fr is possible), high resolution (tens of nanometers can be obtained) and high force density. Furthermore, the fact that the power supply of piezoelectric materials is electrical makes their design and control easy. Finally, piezoelectric devices can be used as a sensor or as an actuator.

Piezoelectric microgrippers are one of the well-known devices utilized in microrobotics and microassembly applications for handling and manipulating micro-objects. A piezoelectric microgripper is generally made up of two collaborative piezoelectric actuators with cantilevered structures. Each cantilever can be bent independently by applying an electrical voltage. The bendings of the two actuators can be afterwards used to manipulate, to pick and to move small objects. Various prototypes of piezoelectric microgrippers have been developed to grasp objects with different shapes and characteristics [1-4]. When using piezoelectric microgrippers, many factors may result in a difficulty to achieve the desired performances: 1) the manipulated object itself affects the dynamics of the actuators [5], 2) small systems like microgrippers are very sensitive to the environment, in particular to the surrounding vibration and to any thermal variation, 3) and nonlinearities (hysteresis and creep) that typify piezoelectric actuators 
make difficult the achievement of good accuracy [6]. It is therefore essential to control the actuators of the piezoelectric microgripper in order to reach the severe performances required in micromanipulation and microassembly applications.

For the success of manipulation of micro-objects, it is recognized that both the positioning and the manipulation force are controlled during the tasks. When using piezoelectric microgripper, this can be achieved by controlling on position one of the two actuators while controlling on force the second one in order to maintain the object and to avoid any damage of the actuator or of the object $[4,7]$. The above mentionned characteristics (nonlinearities, sensitivity to the environment,...) make however very challenging the control of piezoelectric microgrippers. Additionally to these, the lack of convenient sensors for the micro-world in general compromises the efficiency of the controllers since additional uncertainties from the sensors raise.

The control of uncertain systems is traditionally accomplished by means of robust control laws such as $H_{\infty}$ and $\mu$-synthesis. The robustness of these approaches has been proven in several applications (SISO and MIMO systems), including in micromanipulation based on microgrippers $[4,7]$. However the major limitation of such robust control approaches is the derivation of high orders controllers which are not convenient for embedded microsystems [8]. In fact, the complexity of high orders controllers makes them hardly implementable in embedded calculators employed in embedded microsystems. In this paper, we propose an approach based on interval analysis to control piezoelectric microgrippers. The approach consists in modeling the piezoelectric microgripper as an uncertain system where the uncertain parameters are assumed to be bounded by intervals. These bounded uncertain parameters are implicitly linked to the nonlinearities of the piezoelectric actuators, the sensitivity of the microgripper to the object characteristics and to the environment, as well as to the uncertainties raised by the limitated performances of the sensors. The main advantages of this approach is the ease and the natural way to model the uncertain parameters.

Interval analysis has been already introduced in control engineering for modeling, for stability analysis and for control design in uncertain systems. In [9], the modeling of systems with parametric uncertainties using a transfer function with interval parameters has been addressed. The robust stability analysis of systems subjected to uncertain parameters has also been discussed in many works [10-14]. Other works dealing with the robustness on performances can be found in $[8,15,17-19]$. In particular, the work in [15] presented an interesting result on the inclusion of performances of interval systems. In a simple way, this result can be used to design a robust controller ensuring some desired performances specifications. In our pre- vious work [8], we demonstrated that interval tools could be of a great interest in the modeling and control of systems working at the micro-scale where the effect of uncertainties on the systems performances is significant. In this paper, the modeling and the robust controllers design for microgrippers by using interval techniques is proposed. Both the force and the displacement in the microgrippers are considered. While the modeling consists in using intervals to bound the uncertain parameters, the controllers synthesis is based on the performances inclusion theorem [15]. On the one hand, the interval modeling permits an ease and natural way to describe the uncertain parameters by employing a lower and upper bounds. On the other hand, the advantage of the proposed controllers synthesis relative to classical techniques $[4,7]$ is the derivation of low orders controllers that are more convenient for implementation and for real time applications.

The remainder of this paper is organized as follows. In section II, we briefly give some preliminaries on interval arithmetic, interval systems and on the performances inclusion theorem [15] that will be used further. In section III, the piezoelectric microgripper to be used and its actuators are presented. Afterwards, in section IV, we present the interval modeling of the microgripper. This is composed of: the position (deflection) modeling of one actuator, and the force modeling of the second actuator. In section $\mathrm{V}$, the design of a robust controller for the position and the design of a robust controller for force are detailed. The proposed synthesis technique is based on the performances inclusion theorem. Sections VI is devoted to the application of the designed controllers on positioning tasks with consideration of the graspping (manipulation) force. Finally, in section-VII, we apply all the above results to an example of automated pick-and-place task. All along the paper, experimental results validate the efficiency of the proposed method.

\section{BRIEF PRELIMINARIES ON INTERVAL ANALYSIS}

\subsection{Basic Terms and Concepts on intervals}

More details on preliminaries given here can be found in [10] or [20].

A (closed) interval number denoted by $[x]$ is a set of real numbers defined as follows:

$$
[x]=\left[x^{-}, x^{+}\right]=\left\{x \in R / x^{-} \leq x \leq x^{+}\right\}
$$

where $x^{-}$and $x^{+}$are the left and right endpoints of $[x]$ respectively.

$[x]$ is said degenerate if $x^{-}=x^{+}$. By convention, a degenerate interval $[a, a]$ can be defined with the real $a$.

The width of an interval $[x]$ is given by $w([x])=x^{+}-$ $x^{-}$, the midpoint of $[x]$ is given by $\operatorname{mid}([x])=\frac{x^{+}+x^{-}}{2}$ and the radius of $[x]$ is defined by $\operatorname{rad}([x])=\frac{x^{+}-x^{-}}{2}$. 
The elementary mathematical operations can be extended to intervals. Let $[x]=\left[x^{-}, x^{+}\right]$and $[y]=\left[y^{-}, y^{+}\right]$be two intervals and let $\circ \in\{+,-, *, /\}$ be a law. These basic mathematical operations are summarized in Table 1 and give as below:

$$
[x] \circ[y]=\{x \circ y \mid x \in[x], y \in[y]\}
$$

Table 1: Arithmetic operations on intervals [10,20].

\begin{tabular}{|c|c|}
\hline Operation & Definition \\
\hline+ & {$[x]+[y]=\left[x^{-}+y^{-}, x^{+}+y^{+}\right]$} \\
\hline- & {$[x]-[y]=\left[x^{-}-y^{+}, x^{+}-y^{-}\right]$} \\
\hline$*$ & $\begin{array}{l}{[x] *[y]} \\
=\left[\min \left\{x^{-} * y^{-}, x^{+} * y^{-}, x^{-} * y^{+}, x^{+} * y^{+}\right\},\right. \\
\left.\max \left\{x^{-} * y^{-}, x^{+} * y^{-}, x^{-} * y^{+}, x^{+} * y^{+}\right\}\right]\end{array}$ \\
\hline 1 & {$[x] /[y]=[x] *\left[1 / y^{+}, 1 / y^{-}\right], 0 \notin[y]$} \\
\hline
\end{tabular}

\subsection{Interval systems}

Definition 1: Parametric uncertain systems can be modeled by interval systems. A SISO interval system that defines a family of systems is denoted $[G](s,[p],[q])$ and is described by a transfer function with interval parameters as follows:

$$
\begin{aligned}
{[G](s,[p],[q]) } & =\frac{\sum_{j=0}^{m}\left[q_{j}\right] s^{j}}{\sum_{i=0}^{n}\left[p_{i}\right] s^{i}} \\
& =\left\{\frac{\sum_{j=0}^{m} p_{j} s^{j}}{\sum_{i=0}^{n} p_{i} s^{i}} \mid p_{i} \in\left[p_{i}^{-}, p_{i}^{+}\right], p_{j} \in\left[p_{j}^{-}, p_{j}^{+}\right]\right\}
\end{aligned}
$$

Such as: $[q]=\left[\left[q_{0}\right], \ldots,\left[q_{m}\right]\right]$ and $[p]=\left[\left[p_{0}\right], \ldots,\left[p_{n}\right]\right]$ are boxes (i.e. vectors of interval numbers).

The following theorem, called performances inclusion theorem, states the inclusion of performances of two interval systems and is due to [15]. Consider two interval systems having the same structure, i.e. having the same degrees of polynomials:

$$
\left[G_{1}\right](s)=\frac{\sum_{j=0}^{m}\left[b_{1 j}\right] s^{j}}{\sum_{i=0}^{n}\left[a_{1 i}\right] s^{i}} \text { and }\left[G_{2}(s)\right]=\frac{\sum_{j=0}^{m}\left[b_{2 j}\right] \cdot s^{j}}{\sum_{i=0}^{n}\left[a_{2 i}\right] \cdot s^{i}}
$$

Theorem 1: (Performances inclusion theorem)

$$
\begin{gathered}
\text { if }\left\{\begin{array}{l}
{\left[b_{1 j}\right] \subseteq\left[b_{2 j}\right] \forall j=0, \ldots, m} \\
{\left[a_{1 i}\right] \subseteq\left[a_{2 i}\right] \forall i=0, \ldots, n}
\end{array}\right. \\
\Rightarrow\left\{\begin{array}{c}
{\left[g_{1}\right](t) \subseteq\left[g_{2}\right](t) \quad \forall t} \\
\left\{\begin{array}{l}
{[\rho]\left(\left[G_{1}\right](j \omega)\right) \subseteq[\rho]\left(\left[G_{2}\right](j \omega)\right)} \\
{[\varphi]\left(\left[G_{1}\right](j \omega)\right) \subseteq[\varphi]\left(\left[G_{2}\right](j \omega)\right)}
\end{array}\right.
\end{array}\right.
\end{gathered}
$$

where $\left[g_{i}\right](t)$ is the (time) impulse response of system $\left[G_{i}\right](s),[\rho]\left(\left[G_{i}\right](j \omega)\right)$ is its magnitude and $[\varphi]\left(\left[G_{i}\right](j \omega)\right)$ is its phase.

Proof: See [15].

Theorem 1 states that if each interval parameter in $\left[G_{1}\right](s)$ is included in its corresponding parameter in $\left[G_{2}\right](s)$, then the time response (impulse response, step response, etc.) of $\left[G_{1}\right](s)$ will be bounded by that of $\left[G_{2}\right](s)$. The same inclusion holds for the frequency response (Bode, Nyquist, Black-Nichols). In other words, the performance of the system $\left[G_{1}\right](s)$ will be bounded by the performance of the system $\left[G_{2}\right](s)$.

\section{PRESENTATION OF THE PIEZOELECTRIC MICROGRIPPER}

In this section, we present the developed microgripper used in this paper. The microgripper is made up of two similar unimorph piezoelectric cantilevers, also called piezocantilevers. Each actuator can be actuated independently. A unimorph piezocantilever is made up of one piezoelectric layer and one non-piezoelectric (or passive) layer glued themselves. When a voltage is applied to the piezoelectric layer, it contracts or expands depending on the direction of the electrical field. This results in a global deflection of the whole cantilever. The resulting deflection can be used to precisely position a small object that is in contact with the actuated cantilever. Here, the piezocantilevers have a PZT-PIC151 (lead zirconate titanate) piezoelectric layer and a copper material based passive layer. They have thicknesses of $200 \mu \mathrm{m}$ and of $100 \mu \mathrm{m}$ respectively. Sizes of each actuator (piezocantilever) are approximately length $\times$ width $\times$ thickness $=18 \mathrm{~mm} \times 2 \mathrm{~mm} \times$ $0.3 \mathrm{~mm}$. Fig. 1 pictures some of the developed piezocantilevers.

The microgripper is obtained by glueing two piezocantilevers on a double-sided PCB (Printed Circuit Boards) as pictured in Fig. 2-a. The conductive adhesive "EPO-TEK $\mathrm{H} 22 "$ is used as the glue. This facilitates the electrical connection between the piezocantilevers and the PCB.

Fig. 2-b presents a photography of the developed microgripper. In the figure, $x$ is the axis of the gap between both actuators and $y$ is the perpendicular axis. Both actuators can bend along the $x$ axis.

Considering the ranges of deflection of both piezocantilevers, the gap between their tips is chosen to be $350 \mu \mathrm{m}$. This allows to manipulate objects of different sizes. It is 


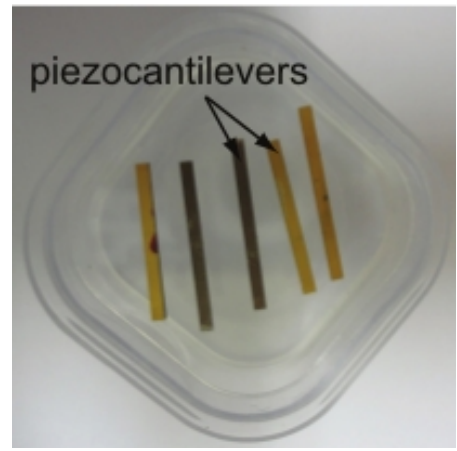

Fig 1: Photography of unimorph piezocantilevers.

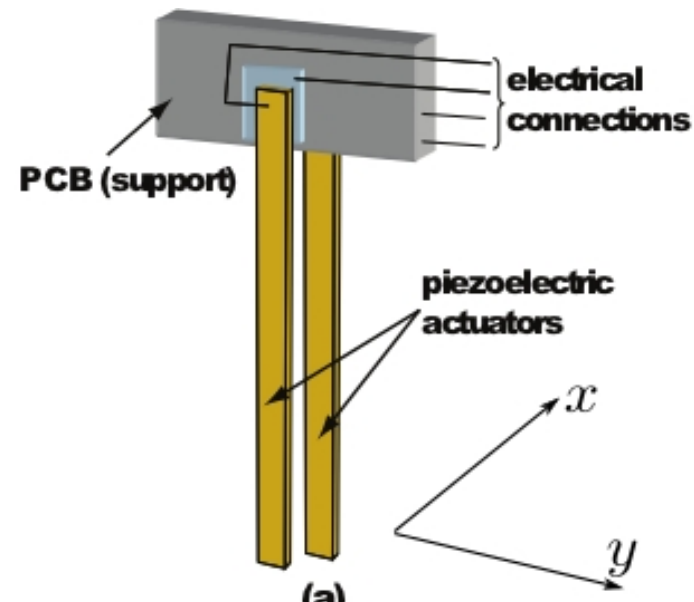

(a)

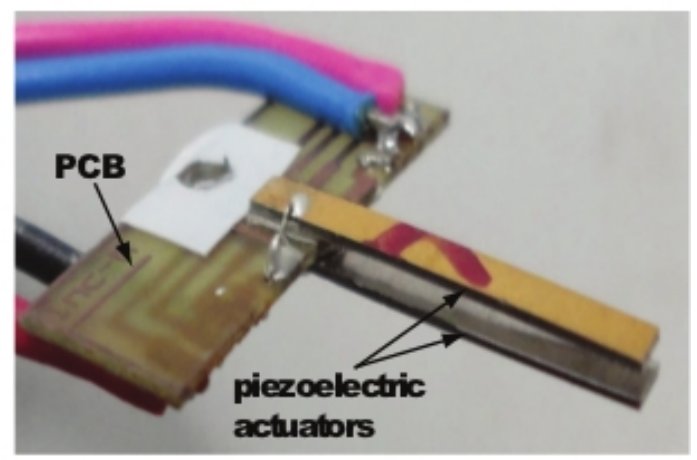

(b)

Fig 2: a: structure of the microgripper using piezocantilevers. b: prototype of the piezoelectric microgripper.

also possible to fix an end-effector at the tip of each actuator in order to easily manipulate objects with different shapes. When positive or negative voltages are applied to the piezocantilevers, the microgripper closes or opens around its initial position allowing the grasping and releasing of an object initially placed within the gap. However, in order to correctly success pick-and-place tasks, it is recommended that one piezocantilever is controlled on position (deflection) and the other one is controlled on ma- nipulation force. In the next sections, we separately give a model and design two controllers for the control of the position and force. In other words, each piezocantilever is independently modeled and controlled: one in position and the second one in force. In the last sections of the paper, both controllers that are independently designed will be employed to perform an automated pick-and-place tasks.

\section{INTERVAL MODELING OF THE MICROGRIPPER}

Let $U_{\delta}$ (resp. $U_{F}$ ) be the input voltage applied to the piezocantilever controlled on position (resp. on force). Furthermore, the output position (deflection) and the manipulation force are denoted by $\delta$ and $F$ respectively. Two approaches are possible to model a microgripper. The first approach is based on the use of one single model that relates the two input voltages $\left(U_{\delta}\right.$ and $\left.U_{F}\right)$ and the two outputs (position $\delta$ and manipulation force $F$ ) as schematized in Fig. 3-a. This multivariable model describes more accurately the microgripper behavior as the coupling between the variables are taken into account. It is therefore possible to find a multivariable controller that can ensure some robust performance requirements for the closed-loop system. However, this approach raises many difficulties due to the fact that it requires to exactly know the properties of the manipulated objects and the interferences between the two actuators. Indeed, for each manipulated object, a characterization and modeling of the microgripper is required. The second approach consists in modeling independently each actuator of the microgripper [7] (see Fig. 3-b) such that one actuator is modeled on deflection while the second one is modeled on force. The main advantage of this approach is the derivation of simpler models, more precisely the derivation of two single-inputsingle-output (SISO) systems which are easier to handle. In this approach, the couplings between variables are considered as external disturbances or internal uncertainties that should be taken into account during the controllers synthesis. This latter approach will be used in the paper.

\subsection{Interval modeling of the voltage-deflection relation- ship}

Notice that all fabricated piezocantilevers (and therefore the two actuators that constitute our microgripper) are similar. Let us therefore assume that the initial models of the two piezocantilevers, linking the input voltage $U_{i}$ and the output deflection $\delta_{i}$ (where the subscript $i=\{1,2\}$ indicates the first or the second actuator), have the same structure. To process, let us consider Fig. 4 where a piezocantilever bends along the $x$ axis when it is subjected to an electrical voltage. The linear relationship linking the input $U_{i}$ and the output $\delta_{i}$ of the piezocantilever is [21]:

$$
\delta_{i}=G_{i}(s) U_{i}
$$




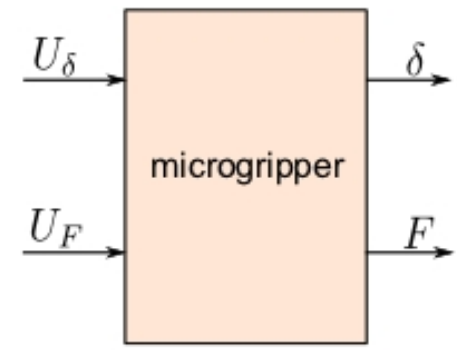

(a)

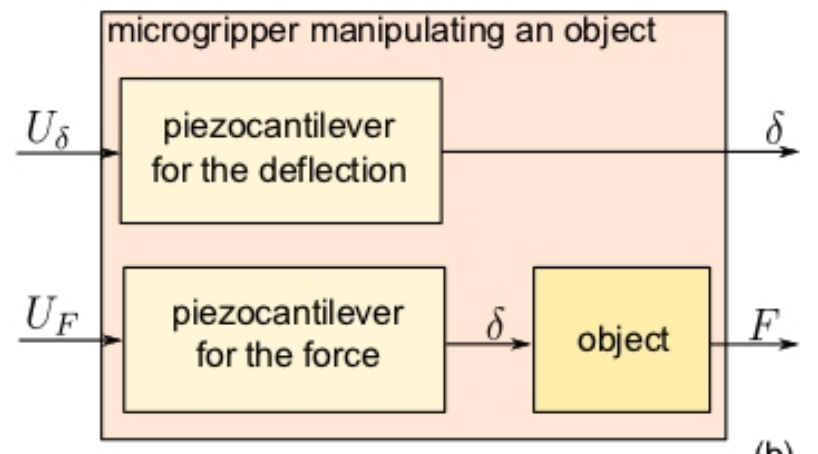

(b)

Fig 3: a: microgripper modeled by a multivariable system. b: microgripper modeled by two independent monovariable systems.

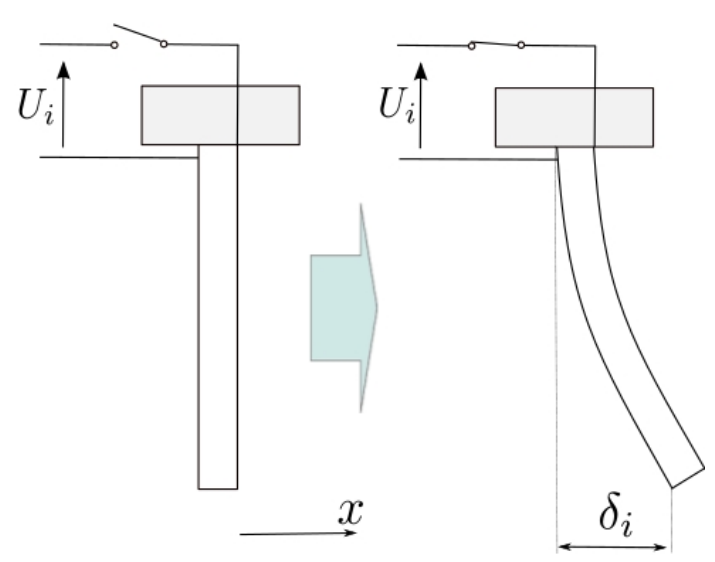

Fig 4: Piezoelectric actuator under electrical excitation.

where $G_{i}$ is a transfer function and $s$ the Laplace variable. The linear model in (4) does not reflect the real behavior of the actuator. This model does not account for the nonlinearities typifying the piezoecantilevers and for the behavior variation due to the environment changes. This model is consequently uncertain. To complete this model, we propose to introduce intervals to bounds the model uncertainties. Let us first identify the parameters (which are not interval parameters) of (4) for each actuator of the microgripper. For that, a step voltage $U_{i}=40 \mathrm{~V}$ is first applied to each piezocantilever, then the resulting output deflection $\delta_{i}$ is measured. The identification of the parameters is performed using the System Identification Toolbox of Matlab and the output error method [22]. In this particular application, a second order model has been chosen because the first resonant mode is assumed here to be sufficient. We obtain:

$$
\begin{aligned}
& G_{1}(s)=\frac{1.421 \times 10^{-4} s+1}{4.88 \times 10^{-8} s^{2}+4.33 \times 10^{-6} s+0.822} \\
& G_{2}(s)=\frac{1.399 \times 10^{-4} s+1}{6.6 \times 10^{-8} s^{2}+4.91 \times 10^{-6} s+0.93}
\end{aligned}
$$

Let us now derive the interval model, $\left[G_{\delta}\right](s)$, which relates the input voltage $U_{i}$ and the output deflection $\delta_{i}$. The aim is to have one model that encloses the two previous models $G_{1}(s)$ and $G_{2}(s)$. For that, we consider each parameter in $G_{1}(s)$ and the corresponding parameter in $G_{2}(s)$ as endpoints of the interval parameter in $\left[G_{\delta}\right](s)$. We obtain:

$$
\left[G_{\delta}\right](s)=\frac{\operatorname{Num}_{\delta}(s)}{\operatorname{Den}_{\delta}(s)}
$$

where

$$
\left\{\begin{array}{l}
\operatorname{Num}_{\delta}(s)=[1.399,1.421] \times 10^{-4} s+1 \\
\operatorname{Den}_{\delta}(s)=[4.88,6.6] \times 10^{-8} s^{2} \\
+[4.33,4.91] \times 10^{-6} s+[0.822,0.93]
\end{array}\right.
$$

Now, we propose to extend the interval parameters in (7) such that we are sure to really bound the two models. Furthermore, in such a way, we increase the range of the modeled uncertainties and then increase the chance to include by other sources (nonlinearities, variation due to the environment, ...). It is worth to notice that if the intervals are too large, finding a suitable controller may not be possible. A compromise should be done between the widths of interval parameters and the existence of a controller. Based on the idea of trial-error, we find that $10 \%$ of extension of each interval parameter width is a good compromise for the example in this paper. Thus, the final interval model to be used for the controller design and that relates the deflection and the voltage has the following polynomials:

$$
\left\{\begin{array}{l}
\operatorname{Num}_{\delta}(s)=[1.3968,1.4232] \times 10^{-4} s+1 \\
\operatorname{Den}_{\delta}(s)=[4.768,6.772] \times 10^{-8} s^{2} \\
+[4.272,4.968] \times 10^{-6} s+[0.8112,0.9408]
\end{array}\right.
$$

Remark 1: The voltage-deflection model described by (6) will be utilized for the piezocantilever controlled on position. This piezocantilever can be any of the set of piezocantilevers since all of them have a model enclosed by the interval model. For the microgripper, this piezocantilever controlled on position can be the left actuator or the right one. The voltage-force model which will be 
derived in the next subsection is also valid for both piezocantilevers of the microgripper. To conclude, if the left (resp. right) piezocantilever is selected as a position actuator, the right (resp. left) piezocantilever should be utilized as the force actuator. The voltage-deflection model in (6) and the voltage-force model of the next subsection are valid for both actuators.

\subsection{Interval modeling of the voltage-force relationship}

Let Fig. 5 presents a piezocantilever manipulating an object with a force $F$.

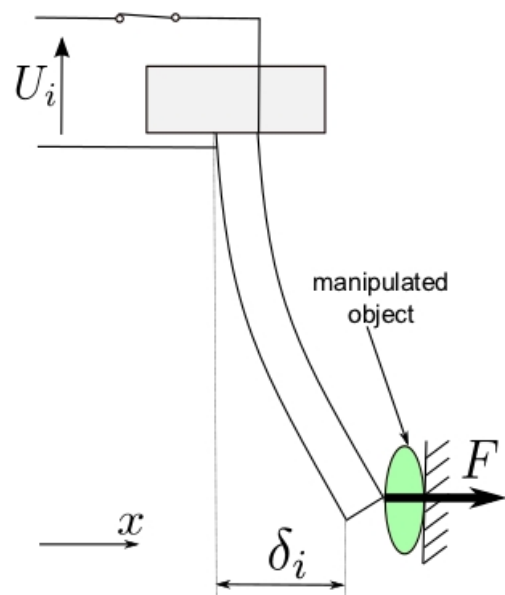

Fig 5: Piezoelectric actuator manipulating an object.

The variables considered in Fig. 5 are:

- $F$ is the force applied by the piezocantilever to the micro-object;

- $\delta$ represents the deflection at the tip of the piezocantilever. Notice that the subscript $i$ is removed for the sake of simplification of notation;

- and $U$ is the voltage applied to the piezocantilever.

When the piezocantilever is in contact with the object, the static relationship that relates the force $F$, the deflection $\delta$ and the applied voltage $U$ is given as follows [7] [23] [24]:

$$
\delta=d_{p} U-s_{p} F
$$

where $s_{p}>0$ is the elastic coefficient of the piezocantilever and $d_{p}$ is the piezoelectric constant.

It has been demonstrated in [1] that the dynamics $D(s)$ of the voltage-deflection $(U, \delta)$ transfer function and the dynamics of the voltage-force $(F, \delta)$ transfer function are equal. Consequently, introducing the dynamics $D(s)$ in (9) yields:

$$
\delta=\left(d_{p} U-s_{p} F\right) D(s)
$$

such that $D(s=0)=1$. The term $d_{p} D(s)$ is the transfer function that relates the deflection $\delta$ of the piezocantilever and the applied input voltage $U$ which is the similar to (4), i.e. $G(s)=d_{p} D(s)$.

According to [23], the deflection $\delta$ can also be expressed as function of the force $F$ and the object characteristics as follows:

$$
\delta \approx s_{o} F
$$

where $s_{o}>0$ is the compliance of the manipulated object. Notice that (11) is valid when no gap exists between the piezocantilever and the object at the initial condition, i.e. at $U=0$. If a gap exists before the manipulation, it is always possible to achieve this condition by applying a variable change [23].

Combining (10) and (11), the force applied to the object can be deduced:

$$
F=\frac{d_{p}}{\frac{s_{o}}{D(s)}+s_{p}} U=G_{F}(s) U
$$

From (12), it is demonstrated that the behavior of a piezoelectric actuator manipulating an object depends on the stiffness $\left(\frac{1}{s_{o}}\right)$ of the object. Any change of manipulated object results in a significant change in the behavior of the actuator. This is why in micromanipulation and microassembly applications based on microgrippers, the performances are strongly affected by the environment. To consider this variablity, we propose to also use intervals to model and to bound the compliance $s_{o}$ :

$$
\left[s_{o}\right]=\left[s_{o}^{-}, s_{o}^{+}\right]
$$

where the left bound $s_{o}^{-}$represents the compliance of the most rigid object while the right bound $s_{o}^{+}$indicates the compliance of the most flexible object.

Remark 2: It is important to account these objects properties if the objective is the modeling and the control of the force. If these object properties are not conveniently considered, the performances of the manipulation system or even the stability will be lost. In this paper, we have proposed to account the compliances of the different objects by bounding them with one interval (see equation (13)). Consequently, we have only one model (interval model) valuable for the actuator and for any object within the set (interval). To identify the values of the compliance interval in equation (13), it suffices to use the compliance of the most flexible object and the compliance of the most rigid object. As soon as a controller from that model is found, the performances (and therefore the stability) will be ensured for any object with property within this set. The main limitation of the method is that when the interval compliance in equation (13) is too large, it may be difficult to find a controller that will ensure the performances for the whole set. In this case, an extension of the proposed method into interval adaptive control method can be proposed.

After introducing $\left[s_{o}\right]$ in (12), we have: 


$$
F=\frac{d_{p}}{\frac{\left[s_{o}\right]}{D(s)}+s_{p}} U
$$

The model in (14) is with point parameters, except the compliance parameter which is interval. The model is therefore valuable for a set of objects but only with one piezocantilever. If we want to extend the validity of the model for a set of piezocantilevers, we also replace the dynamics $D(s)$ and the parameters $s_{p}$ and $d_{p}$ into intervals. This has already been introduced in the previous subsection during the position modeling. Thus, (14) becomes:

$$
[F]=\frac{\left[d_{p}\right]}{\frac{\left[s_{o}\right]}{[D](s)}+\left[s_{p}\right]} U=\left[G_{F}\right](s) U
$$

Let us first characterize and define the interval of the elastic coefficient $\left[s_{p}\right]$. The derivation of such an interval $\left[s_{p}\right]$ is based on the identification of the compliances $s_{p_{i}}, i=1,2$ of both piezocantilevers of the microgripper. To identify the compliance of a piezocantilever, a known mass $m$ is first placed at its tip then the resulting deflection $\delta$ is measured. Using the mass $m$ and the measured deflection $\delta$, the compliance can be derived $s_{p}=\frac{\delta}{m \cdot g}$, where $g$ is the terrestrial gravitational constant. In this application, a standard mass of $m=20 \mathrm{mg}$ has been used, which leads to the following compliances: $s_{p_{1}}=\frac{\delta_{1}}{\mathrm{~m} \cdot \mathrm{g}}=1.3 \mu \mathrm{m} / \mathrm{mN}$ and $s_{p_{2}}=\frac{\delta_{2}}{m \cdot g}=1.3 \mu \mathrm{m} / \mathrm{mN}$. As we can see, the coefficients obtained are equal, which means that the compliance is a degenerate interval:

$$
\left[s_{p}\right]=s_{p}=[1.3,1.3] \mu m / m N=1.3 \mu m / m N
$$

The piezoelectric constant $\left[d_{p}\right]$ and the dynamics $[D](s)$ can directly be deduced from the model $[G](s)$ in (8). Since $[G](s)=\left[d_{p}\right][D](s)$, we obtain from (8):

$$
\left[d_{p}\right]=[1.0752,1.2166]
$$

and

$$
[D](s)=\frac{[1.3968,1.4232] \times 10^{-4} s+1}{[5.1266,8.2388] \times 10^{-8} s^{2}+[4.593,6.044] \times 10^{-6} s+1}
$$

In this paper, we use two objects. The most elastic object is made based on polystyrene material while the most rigid object is a CMS resistance (see Fig. 6).

After identifying their compliances, the following interval parameter is obtained:

$$
\left[s_{o}\right]=[1.93,3.738] \mu \mathrm{m} / \mathrm{mN}
$$

Finally, the interval model (15) becomes:

$$
\left[G_{F}\right](s)=\frac{\operatorname{Num}_{F}(s)}{\operatorname{Den}_{F}(s)}
$$

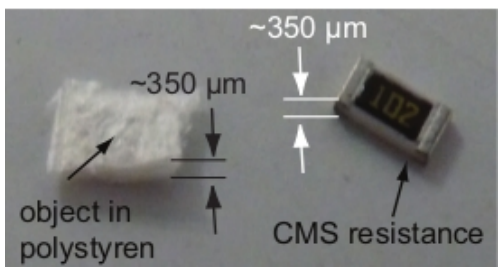

Fig 6: Manipulated objects: a flexible object (polystyrene) and a rigid (CMS resistance) object.

with

$$
\left\{\begin{array}{l}
\operatorname{Num}_{F}(s)=[1.399,1.421] \times 10^{-4} s+1 \\
\operatorname{Den}_{F}(s)=[0.94,2.46] \times 10^{-7} s^{2}+[2.78,2.92] \times 10^{-4} s+[3.51,5.4]
\end{array}\right.
$$

\section{CONTROLLER DESIGN USING INTERVAL ANALYSIS}

In the previous section, two interval models have been derived: 1) the interval model that relates the input voltage (denoted $U_{\delta}$ in the sequel) and the deflection $\delta$ (see $(6)), 2)$ and the interval model that relates the input voltage (denoted $U_{F}$ in the sequel) and the manipulation force $F$ (see (20)). These models can be indifferently used for the left or the right piezocantilever of the microgripper. In this section, the first model is utilized to design a controller for the position, while the second model is used to design another controller for the force. The uncertainties are defined thanks to the interval parameters of the models and if the controllers exist, they will be robust face to these uncertainties. In this paper, each controller is designed on the basis of the performances inclusion theorem reminded in Theorem 1.

\subsection{Controller design for the deflection}

Consider the scheme pictured in Fig. 7-a, in which the deflection of the actuator is enslaved by a controller $C_{\delta}(s)$. In the figure, $\delta_{c}$ represents the reference input. Fig. 7-b shows the corresponding block diagram that will be used for the synthesis, where $\left[G_{\delta}\right](s)$ is the interval model to be controlled.

The objective is to design a robust controller that ensures the following closed-loop performances specifications for any piezocantilever having a model lying in the interval model $\left[G_{\delta}\right](s)$ :

- closed-loop behavior with very small overshoot,

- settling time: $t_{r} \leq 20 \mathrm{~ms}$,

- bounded steady state error: $|\varepsilon| \leq 1 \%$.

A major advantage of the utilized technique here is that we can impose the structure of the controller, i.e. we can 

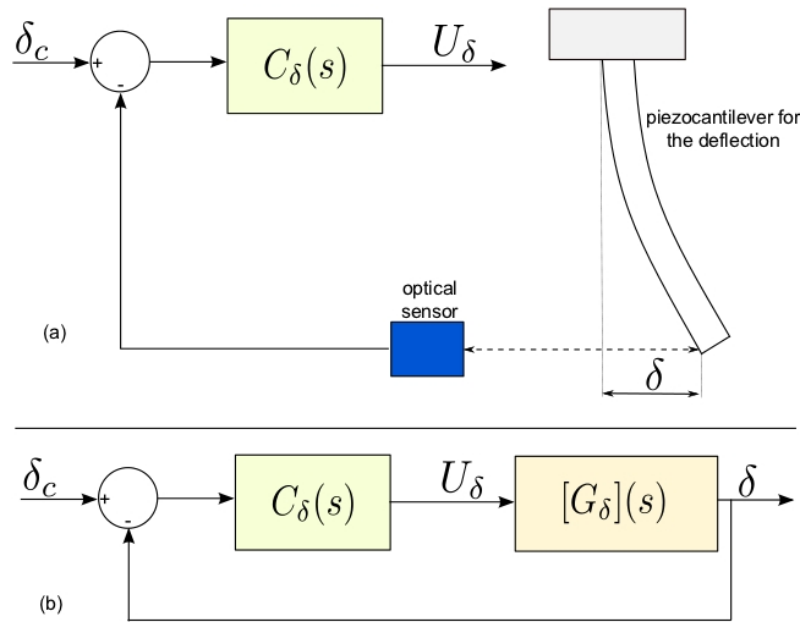

Fig 7: (a): deflection control of the piezoelectric actuator. (b): equivalent block diagram used for the controller synthesis.

impose its order. Let us choose a PI (proportional-integral) controller $C_{\delta}(s)=\frac{K_{p} s+K_{i}}{s}$, where $K p$ and $K_{i}$ are the proportional and the integral gains respectively. This choice is motivated by its simple structure (low order, only two parameters to be calculated) and its ability to ensure zero statical (steady-state) error thanks to the integral action. In general, when synthesizing a controller from an interval model $\left[G_{\delta}\right](s)$, an interval controller is yielded. The reason is that interval tools and techniques yield interval solutions. Let us therefore rewrite the controller as the following interval controller:

$$
\left[C_{\delta}\right](s)=\frac{\left[K_{p}\right] s+\left[K_{i}\right]}{s}
$$

where $[K p]$ and $\left[K_{i}\right]$ are the interval proportional and integral gains respectively. The interval controller $\left[C_{\delta}\right](s)$ itself is not implementable but any point controller $C(s)$ inside this $\left(C(s) \in\left[C_{\delta}\right](s)\right)$ will be and will satisfy the performances.

It is worth to mention that PI controller structure is very common in many applications and there are many methods to tune its parameters. An advantage of the technique dealt in this paper to tune PI controllers is the robustness face to uncertainties defined by intervals.

Let us first compute the closed-loop system using the interval model $\left[G_{\delta}\right](s)$ given in (6) and the PI controller $\left[C_{\delta}\right](s)(22)$. We obtain:

$$
\left[H_{c l}\right](s)=\frac{1}{\left(\frac{1}{\left[G_{\delta}\right]\left[C_{\delta}\right]}+1\right)}=\frac{\operatorname{Num}_{c l}(s)}{\operatorname{Den}_{c l}(s)}
$$

with:

$$
\left\{\begin{array}{l}
\operatorname{Num}_{c l}(s)=\frac{\left[K_{p}\right]}{\left[K_{i}\right]}[1.399,1.421] \times 10^{-4} s^{2} \\
+\left(\frac{\left[K_{p}\right]}{\left[K_{i}\right]}+[1.399,1.421] \times 10^{-4}\right) s+1 \\
\operatorname{Den}_{c l}(s)=\frac{1}{\left[K_{i}\right]}[4.88,6.6] \times 10^{-8} s^{3} \\
+\frac{1}{\left[K_{i}\right]}\left([4.33,4.91] \times 10^{-6}+\left[K_{p}\right][1.399,1.421] \times 10^{-4}\right) s^{2} \\
+\left(\frac{\left(\left[K_{p}\right]+[0.822,0.93]\right)}{\left[K_{i}\right]}+[1.399,1.421] \times 10^{-4}\right) s+1
\end{array}\right.
$$

Let us also transcribe the above specified performances for the closed-loop system into an interval transfer function denoted $\left[H_{r}\right](s)$ and called interval reference model. A first order system can sufficiently approximate such performances:

$$
\left[H_{r}\right](s)=\frac{\left[K_{e}\right]}{(1+[\tau] s)}
$$

where $\left[K_{e}\right]$ and $[\tau]$ are calculated from the desired steady state error and settling time respectively as follows:

$$
\left\{\begin{array}{l}
{[\tau]=\left[0, \frac{t_{r}}{3}\right]=[0,0.007]} \\
{\left[K_{e}\right]=[1-|\varepsilon|, 1+-|\varepsilon|]=[0.99,1.01]}
\end{array}\right.
$$

The computation of the controller parameters $\left[K_{p}\right]$ and $\left[K_{i}\right]$ is based on the performances inclusion theorem (Theorem 1). The objective here is to find suitable values of $\left[K_{p}\right]$ and $\left[K_{i}\right]$ such that the closed-loop system $\left[H_{c l}\right](s)$ satisfies the specified performances in $\left[H_{r}\right](s)$. According to theorem Theorem 1, this problem can be formulated as follows: find the parameters $\left[K_{p}\right]$ and $\left[K_{i}\right]$ such that each parameter of $\left[H_{c l}\right](s)$ is enclosed by the counterpart parameter in the interval reference model $\left[H_{r}\right](s)$. This latter problem is however not well-posed if $\left[H_{c l}\right](s)$ and $\left[H_{r}\right](s)$ do not have the same structure, i.e. if their numerators (resp. denominators) do not have the same polynomial degree. In our case, the problem is not well-posed since $\left[H_{c l}\right](s)$ has two zeros and three poles (see (24)) while $\left[H_{r}\right](s)$ does not have a zero and has only one pole (see (25)). To render this problem well-posed, we propose to add two zeros and two poles to the interval reference model $\left[H_{r}\right](s)$. These additional zeros and poles should be very quick (far away from the imaginary axis) compared to the actual zeros and poles of $\left[H_{r}\right](s)$ in order to not affect the desired settling time $t_{r}$. Finally, we propose to use the following structure for the interval reference model:

$$
\left[H_{r}\right](s)=\frac{\left[K_{e}\right]\left(1+\frac{[\tau]}{10} s\right)^{2}}{(1+[\tau] s)\left(1+\frac{[\tau]}{10} s\right)^{2}}
$$

which can be rewritten as follows: 


$$
\left[H_{r}\right](s)=\frac{0.01[\tau]^{2} s^{2}+0.2[\tau] s+1}{\frac{0.01[\tau]^{3}}{\left[K_{e}\right]} s^{3}+\frac{0.21[\tau]^{2}}{\left[K_{e}\right]} s^{2}+\frac{1.2[\tau]}{\left[K_{e}\right]} s+\frac{1}{\left[K_{e}\right]}}
$$

Applying the performances inclusion theorem in Theorem 1, the problem consists in finding $\left[K_{p}\right]$ and $\left[K_{i}\right]$ such that $\left[H_{c l}(s)\right] \subseteq\left[H_{r}\right](s)$, with $\left[H_{c l}\right](s)$ defined by (23) and $\left[H_{r}\right](s)$ defined by $(28)$. This problem is equivalent to finding $\left[K_{p}\right]$ and $\left[K_{i}\right]$ such that:

$$
\left\{\begin{array}{l}
\frac{\left[K_{p}\right]}{\left[K_{i}\right]}[1.399,1.421] \times 10^{-4} \subseteq 0.01[\tau]^{2} \\
\left(\frac{\left[K_{p}\right]}{\left[K_{i}\right]}+[1.399,1.421] \times 10^{-4}\right) \subseteq 0.2[\tau] \\
\frac{1}{\left[K_{i}\right]}[4.88,6.6] \times 10^{-8} \subseteq \frac{0.01[\tau]^{3}}{\left[K_{e}\right]} \\
\frac{1}{\left[K_{i}\right]}\left([4.33,4.91] \times 10^{-6}+\left[K_{p}\right][1.399,1.421] \times 10^{-4}\right) \subseteq \frac{0.2}{\left[K_{e}\right.} \\
\left(\frac{\left(\left[K_{p}\right]+[0.822,0.93]\right)}{\left[K_{i}\right]}+[1.399,1.421] \times 10^{-4}\right) \subseteq \frac{1.2[\tau]}{\left[K_{e}\right]} \\
1 \subseteq \frac{1}{\left[K_{e}\right]}
\end{array}\right.
$$

Remark that the steady state error is always null $\left(\left[H_{c l}\right](s=\right.$ $0)=1$ ) thanks to the presence of the integral action in the controller. This can also be verified using the last inclusion of $\left(29: \frac{1}{\left[K_{e}\right]}=\frac{1}{[0.99,1.01]}=[0.99,1.01] \supseteq 1\right.$. The problem of finding $\left[K_{p}\right]$ and $\left[K_{i}\right]$ will therefore be done with the remaining inclusions of (29). The problem is a set inversion problem, i.e. finding a solution of set of points or of intervals in functions. A set inversion problem can be solved using interval tools and techniques. For instance, the SIVIA algorithm (set inversion via interval analysis) [26] can be employed to solve the above problem (29). The algorithm requires an initial box (initial vector of intervals) and an accuracy of computation. After the application of this algorithm with an initial box $\left[K_{p o}\right] \times\left[K_{i o}\right]=$ $[0.1,0.6] \times[0,500]$, we obtain results shown in Fig. 8. In this figure, the area $S_{c}$ corresponds to the solution of parameters $\left[K_{p}\right] \times\left[K_{i}\right]$ of the controller $\left[C_{\delta}\right](s)$ for which the desired closed-loop performances specifications are met. The controller being interval, it cannot be directly implementable. However, any arbitrary choice of parameter values $K_{p}$ and $K_{i}$ within the solution $S_{c}$ provide an implementable controller $C_{\delta}(s)=\frac{K_{p} s+K_{i}}{s}$ that is guaranteed to ensure the performances. In this example, we choose the following controller to be implemented for the position control:

$$
C_{\delta}(s)=\frac{0.2 s+200}{s}
$$

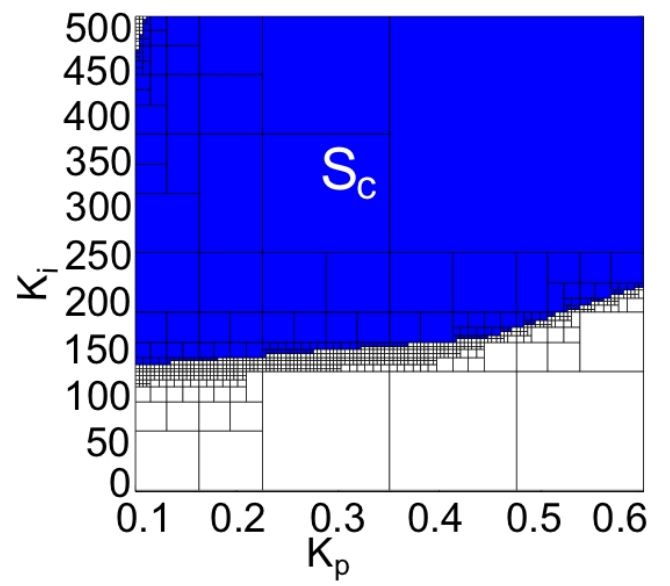

Fig 8: Solution set of parameters $\left[K_{p}\right] \times\left[K_{i}\right]$ of the controller that ensures the specified performances.

Remark 3: If no controller can be found during the ynthesis, the following steps are proposed.

- 1) Restart the computation of the controller using other initial boxes $\left[K_{p o}\right] \times\left[K_{i o}\right]$. It is possible that the initial box previously used did not contain the solution $S_{c}$.

- 2) If the problem is still not feasible even after trying different initial boxes, it is possible that the imposed structure of the controller is not appropriate for solving the problem. The actual controller structure (in this example, a PI-structure) should be changed into a higher order structure.

- 3) It is also possible that the specified performances specifications were too severe. In such a case, a relaxation of the specifications is recommended before recalculating a controller.

\subsection{Controller design for the force}

In the force control design, we use the scheme pictured in Fig. 9-a. In this figure, $F_{c}$ represents the reference of the closed-loop system and $C_{F}(s)$ the controller to be computed. Due to the lack of convenient force sensor, we propose to employ a force observer devoted to piezocantilevers. The force observer as we proposed and demonstrated in $[27,28]$ is independent from the object characteristics. Furthermore, the force observer is 'closed loop'. The technique, called uknown input observer based on the inverse dynamics, consists in considering the force as an unknown input disturbance and then estimating this latter by inverse dynamics. The convergence of the estimate force has been demonstrated and a set of experimental results have confirmed the observer technique. The observer has at its inputs the input voltage $U_{F}$ and the measured deflection $\delta$. Fig. 9-b presents the block diagram of the feedback control. The model which will be used for the controller synthesis is the interval model $\left[G_{F}\right](s)$ defined in (20). The use of this interval model allows us to find to 
a robust controller for a set of piezocantilevers, including the two piezoecantilevers of the microgripper, and also for a set of manipulated objects having compliances within the interval defined in (19).

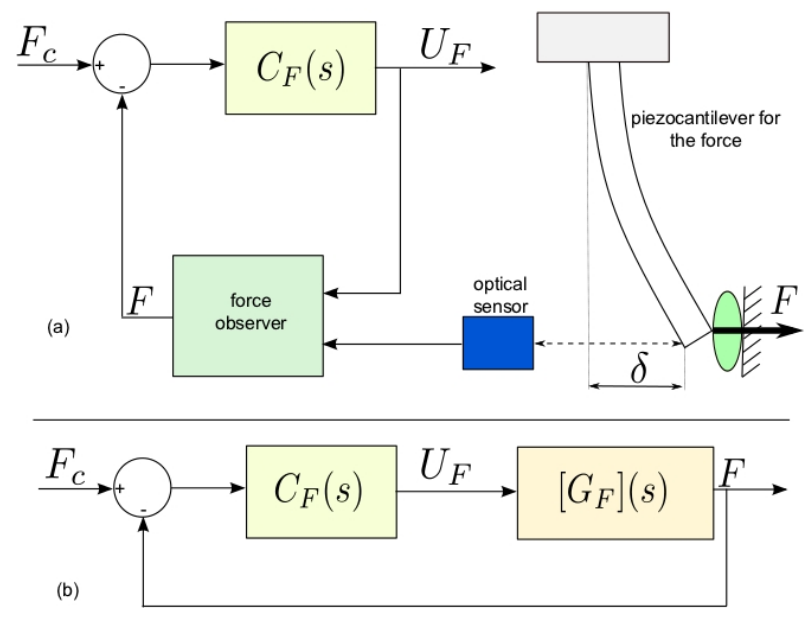

Fig 9: (a): force control of a piezoelectric actuator. (b): equivalent block diagram used for the synthesis.

The following closed-loop performances specifications are considered for the force control:

- negligible overshoot;

- settling time: $t_{r} \leq 8 \mathrm{~ms}$;

- and bounded steady state error: $|\varepsilon| \leq 1 \%$.

Remark 4: We have chosen a faster settling time for the force control compared to that of the deflection. This permits to be sure that the object is always maintained between the two piezocantilevers of the microgripper during a pick-and-place task. Indeed, when a deflection reference is applied to one of the actuators, the other actuator must react faster in order to avoid a release of the manipulated object.

For the controller $C_{F}(s)$, a proportional-integral (PI) structure is also chosen. The controller has been calculated using exactly the same procedcure than in the previous subsection concerning the deflection controller. A solution set $S_{c}$ corresponding to the parameters $\left[K_{p}\right] \times\left[K_{i}\right]$ was first obtained. Then, we choose from this set point parameters $K_{p}=0.2$ and $K_{i}=1500$ for the implemented controller. We obtain:

$$
C_{F}(s)=\frac{0.2 s+1500}{s}
$$

\section{CONTROL OF THE MICROGRIPPER}

The previous section was devoted to the design and calculation of two controllers $C_{\delta}(s)$ and $C_{F}(s)$ for the control of the position and force, respectively. If $C_{\delta}(s)$ (resp. $\left.C_{F}(s)\right)$ is applied to the left piezocantilever of the microgripper, $C_{F}(s)\left(\right.$ resp. $\left.C_{\delta}(s)\right)$ must be applied to the right piezocantilever. In this section, the two designed controllers are implemented and applied to both actuators of the microgripper. Experimental tests are carried out to demonstrate their efficiency for position and force regulations when manipulating an object. For that one actuator is controlled on position, while the second one is controlled on force. Two objects are successively manipulated: a flexible object (polystyrene) and a rigid object (CMS resistance). Fig. 10 shows the setup used for the experiments. The setup is composed of:

- the microgripper with its two piezocantilevers;

- two optical sensors (Keyence LK2420) with a resolution of $10 \mathrm{~nm}$ and an accuracy of $0.1 \mu \mathrm{m}$. The two sensors are used to measure the deflections of the two piezocantilevers;

- a dSPACE board and a computer with Matlab/Simulink used to acquire in real-time data from the sensors, to generate the control signals $U_{\delta}$ and $U_{F}$, to implement the controllers $C_{\delta}(s)$ and $C_{F}(s)$, and to implement the force observer as well. The refresh time of the dSPACE-board and of the Matlab/Simulink is set to $0.2 m s$. This value is sufficiently small to account for the dynamics of the piezoelectric actuators;

- and two high voltage amplifiers $\pm 200 \mathrm{~V}$ that amplify the signals from the dPSACE/computer to supply the two actuators.

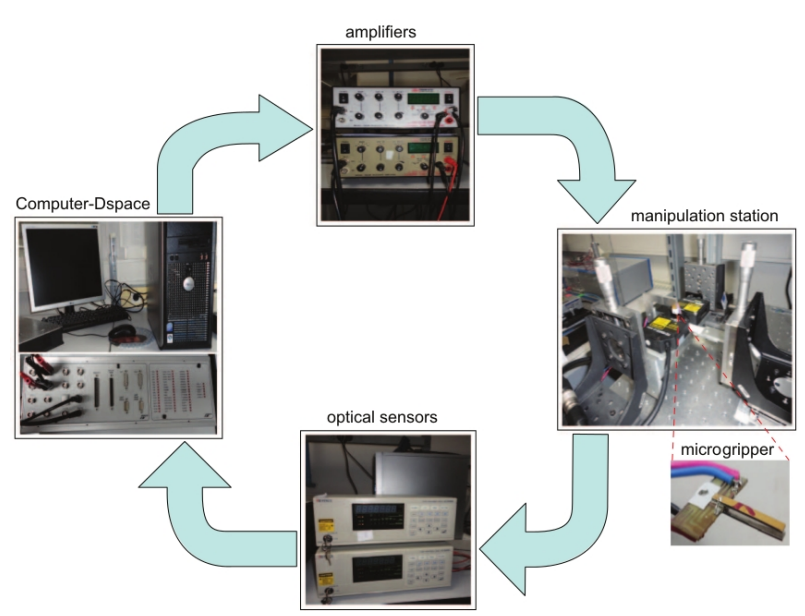

Fig 10: Setup for the experiments.

Fig. 11 depicts a diagram for the control of the whole microgripper.

\subsection{Regulation of the deflection}

During the manipulation of an object by the microgripper, there is a coupling between the two piezocantilevers: a change in the deflection $\delta$ of one actuator disturbs the manipulation force $F$ at the other actuator, and conversely a change in the manipulation force disturbs the deflection. 


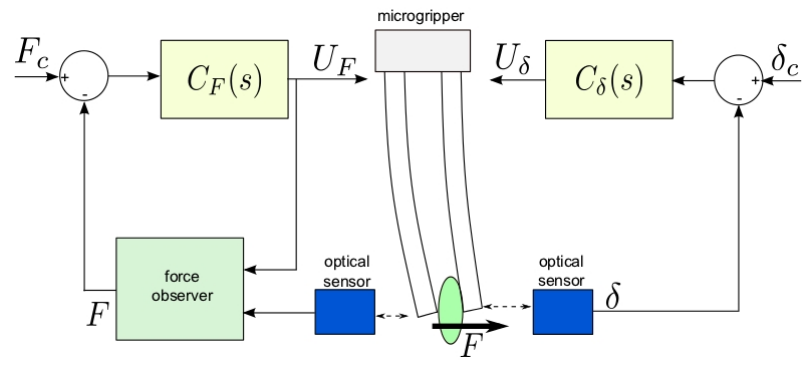

Fig 11: Principle of the microgripper control.

In this subsection, the aim is to characterize the performances on the deflection when the manipulation force is varied.

First, we use the CMS resistance as the manipulated object (rigid object). The deflection and force are initially null. Then, a deflection step reference $\delta_{c}=20 \mu \mathrm{m}$ is applied to the piezocantilever controlled on deflection. Afterwards, a series of constant force reference $F_{c}$ is applied to the other actuator and the effect of this force on the first actuator is observed. Fig. 12 pictures the results. At the time we apply the deflection reference of $\delta_{c}=20 \mu \mathrm{m}$ (at $t \approx 0.45 s$ ), an effect is observed on the force response and is afterwards quickly rejected. During the series of steps for the force reference $F_{c}$, an effect is also observed on the deflection but is still quickly rejected.
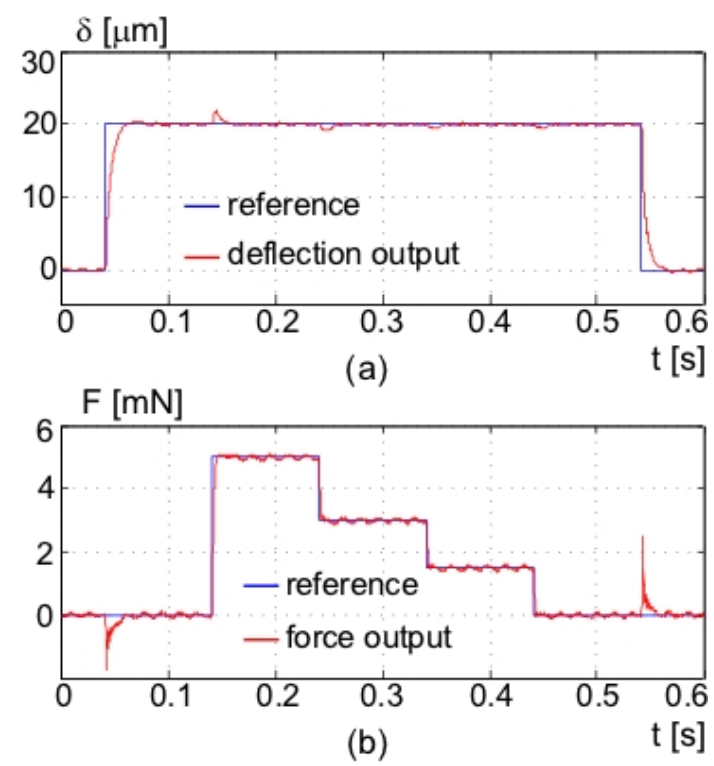

Fig 12: Regulation of the deflection using the CMS resistance. a: deflection reponse. b: force response.

To evaluate the obtained closed-loop performances, a zoom is taken from a deflection and force step responses in Fig. 12. The zoom are shown in Fig. 13. As we can see, the specifications were satisfied. Indeed, the overshoots and static errors are neglected, whereas settling times obtained are $14.4 \mathrm{~ms}$ and $4.1 \mathrm{~ms}$ for the deflection response and force response respectively.
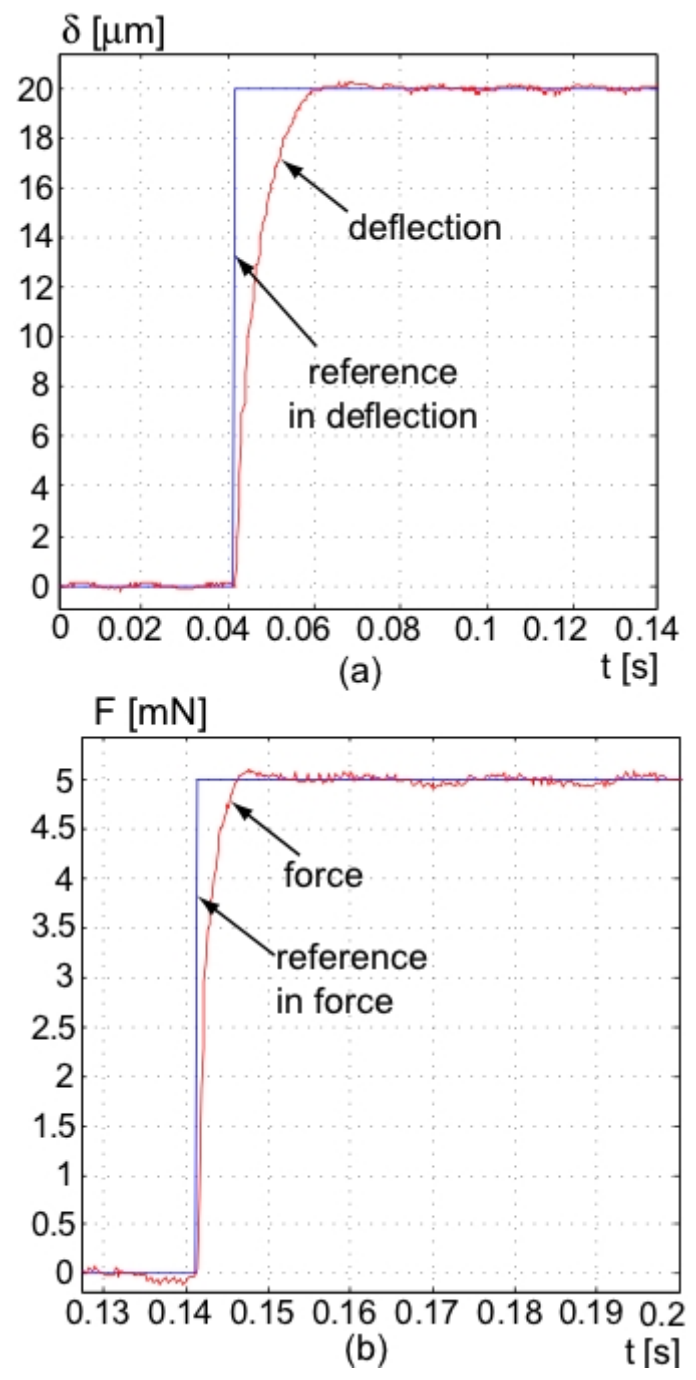

Fig 13: a: zoom on a deflection response. b: zoom on a force response.

Now, we consider the polystyrene (flexible object) as the manipulated object. The same experimental procedure than with the rigid object is followed. The experimental results are presented in Fig. 14 and the zoom on the step responses are presented in Fig. 15. Once again, the specifications are satisfied with the flexible object in term of tracking performances and disturbance rejection. Indeed, the experimental settling times are $16.3 \mathrm{~ms}$ and $4.1 \mathrm{~ms}$ for the deflection and force control respectively while the overshoots and static errors are close to zero.

\subsection{Regulation of the force}

In this subsection, we characterize the behavior on the force when a deflection variation occurs. The two previous objects (CMS resistance rigid object, and the polystyrene flexible object) are still used. The experimental procedure is as follows. Initially we have $\delta=0$ and $F=0$. Then, a force step reference of $5 \mathrm{mN}$ is applied to the actuator con- 


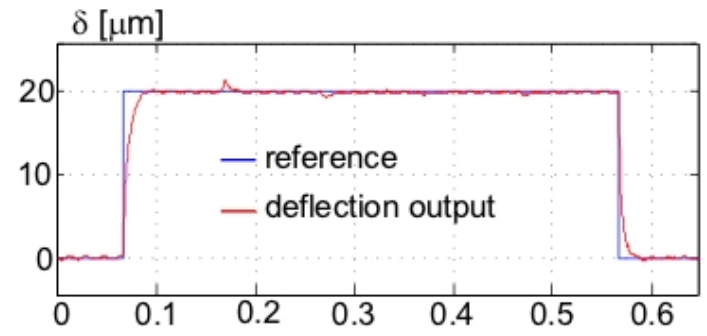

(a)

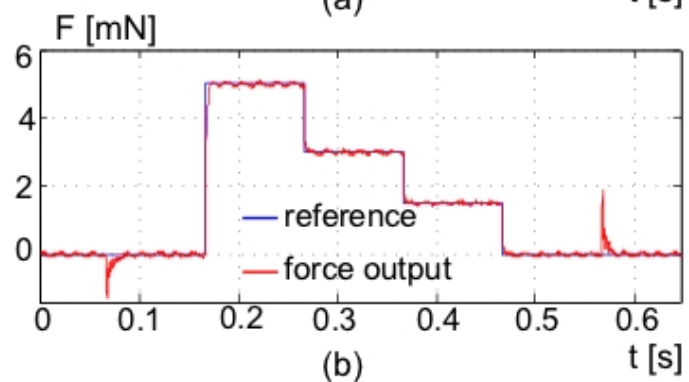

Fig 14: Regulation of the deflection using the flexible object (polystyrene). a: deflection reponse. b: force response.

trolled on force. Afterwards, a series of variations of the deflection reference is applied to the other actuator. The effect of this deflection variations on the force behavior is finally observed and analyzed. The experimental results are presented in Fig. 16 for the rigid object and in Fig. 17 for the flexible object. From these figures, it is observed that any deflection variation has an effect on the force but this effect is quickly rejected thanks to the force controller $C_{F}(s)$. Furthermore, we see that the specifications in terms of overshoot, steady state error and settling time have been satisfied. Indeed, the overshoot and steady state error are neglected with both manipulated objects, while th experimental settling times are:

- about $13.7 \mathrm{~ms}$ and $3.8 \mathrm{~ms}$ for the deflection and for the force respectively, when manipulating the CMS resistance rigid object,

- $16.9 \mathrm{~ms}$ and $3.2 \mathrm{~ms}$ for the deflection and for the force respectively, when manipulating the polystyrene flexible object.

To summarize, the calculated controllers $C_{\delta}(s)$ and $C_{F}(s)$ have ensured the specified performances for the two piezoecantilevers of the microgripper for any manipulated object (rigid or flexible) with property defined in the interval compliance in (19). The experimental results in Fig. 12, Fig. 13, Fig. 14, Fig. 15, Fig. 16 and Fig. 17 demonstrate this fact. The peaks pictures in Fig. 12, Fig. 14, Fig. 16 and Fig. 17 correspond to the couplings (effect of the force of one actuator on the deflection of the other actuator, or conversely). But as expected, these peaks are quickly rejected and the deflection or the force comes back to the reference in order to maintain the accuracy.
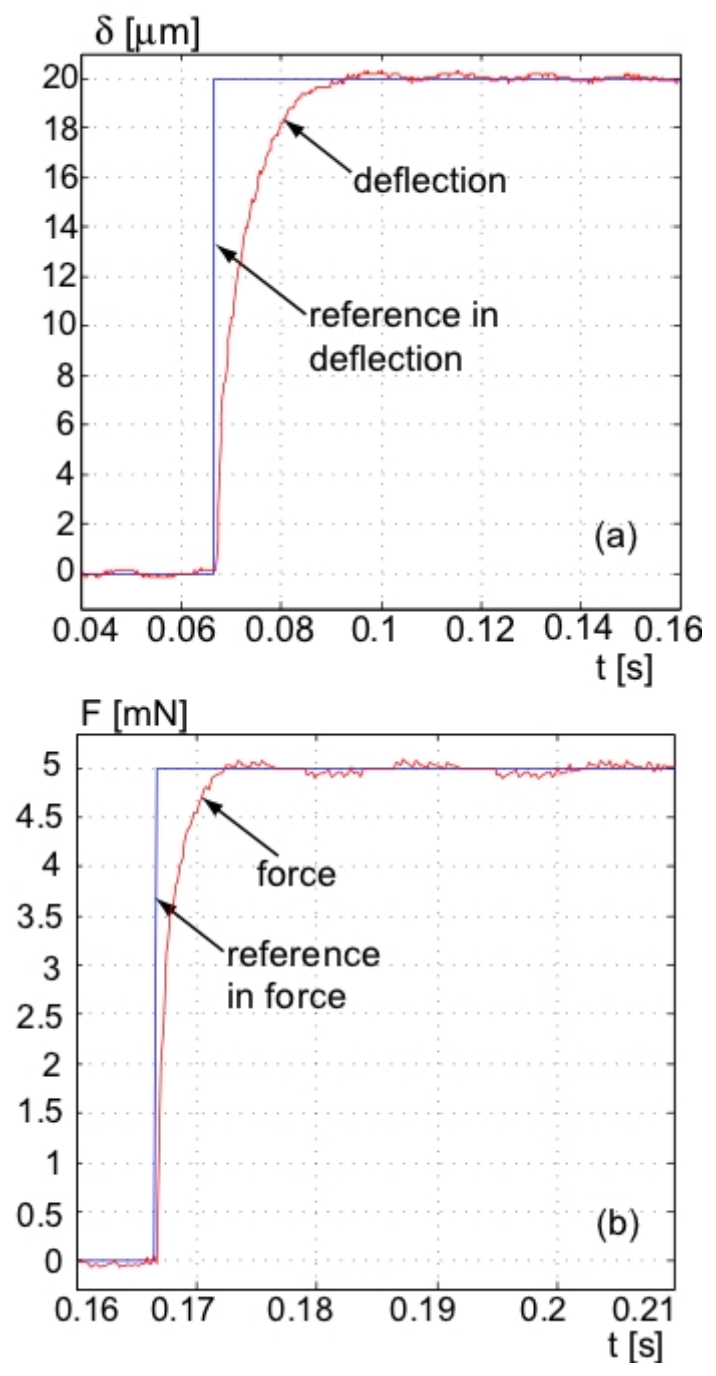

Fig 15: a: zoom on the deflection response. b: zoom on the force response.

\section{COMPLETE AUTOMATED PICK-AND-PLACE TASK}

The objective of this section is to perform an automated pick-and-place task with the controlled microgripper. The task consists in picking, transporting and positioning a small object from an initial location to another desired location. The pick-and-place operation is carried out with a wire (object) having a diameter of $250 \mu \mathrm{m}$. For that, the following procedure is proposed.

- Initially, the wire is located between the two actuators of the microgripper. There is no contact between them and the wire because its diameter is smaller than the gap between the two actuators. Without loss of generality, we assume that the position of the object (wire) is in the center of the microgripper. Thus, the remaining distance between the object and each actuator is approximately $50 \mu \mathrm{m}$. If the initial position of the object is not known, a visual detection 

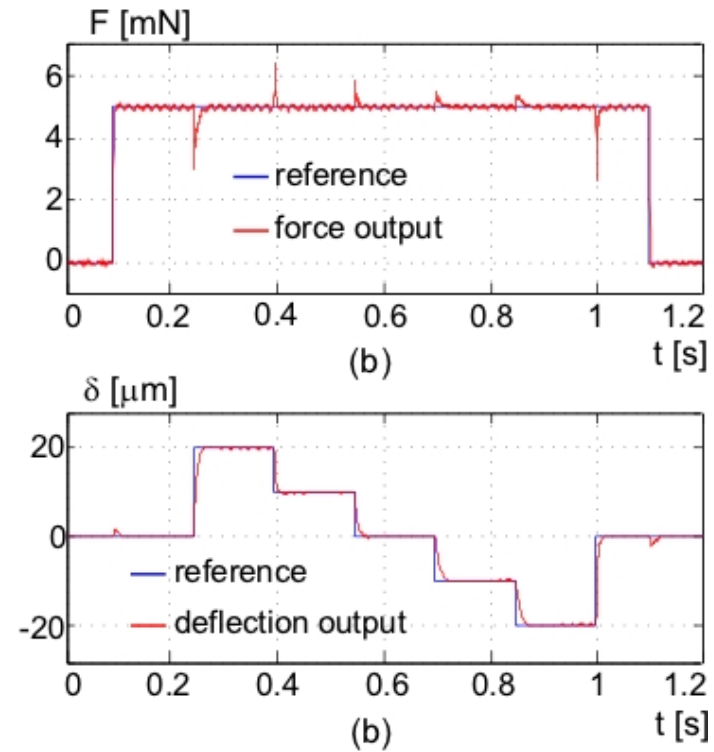

Fig 16: Regulation of the force using the CMS resistance. a: deflection response. b: force response.
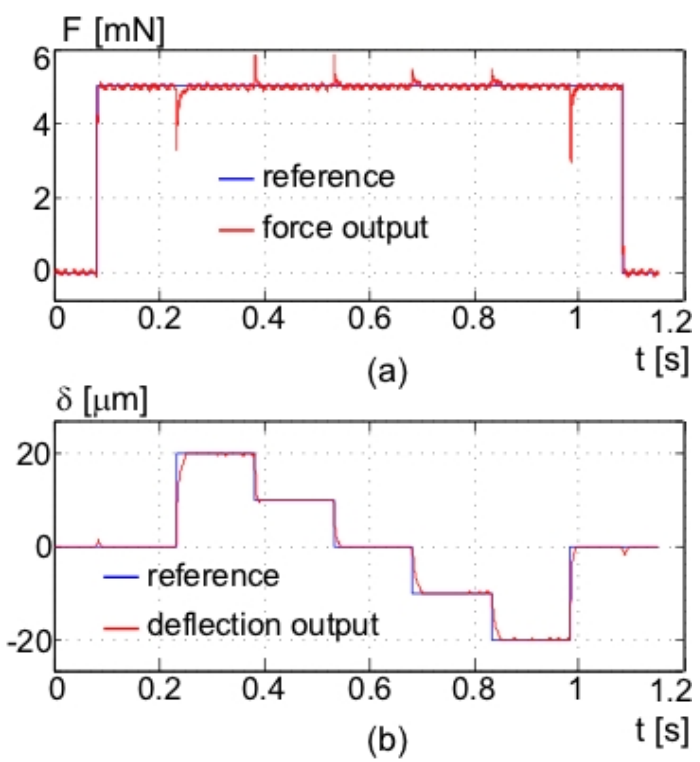

Fig 17: Regulation of the force using the polystyrene object. a: deflection response. b: force response.

method (camera-microscope-visual calculation) can for example be employed.

- Then, a deflection reference is applied to one actuator and a force reference is applied to the other actuator of the microgripper. These references allow us to bring both actuators to be in a slight contact with the wire. To avoid any sudden shock at the moment of the contact however, these two reference signals are chosen to be a ramp with a limit value as shown in Fig. 18. The amplitude of the force reference is set to $F_{c}=1 \mathrm{mN}$ in order to obtain a very slight contact with the wire. The reference for the deflection is set to $50 \mu \mathrm{m}$. This corresponds to the above mentioned distance between the object and the actuator. The actuators of the microgripper are in contact with the wire if the deflection and force reach their specified reference values with the following steady state errors: $\varepsilon_{\delta}=0.1 \mu \mathrm{m}$ and $\varepsilon_{F}=0.3 \mathrm{mN}$. These steady state errors were chosen according to the accuracy of the deflection sensor and of the force observer. Fig. 19-a shows the two piezocantilevers approaching towards the wire.

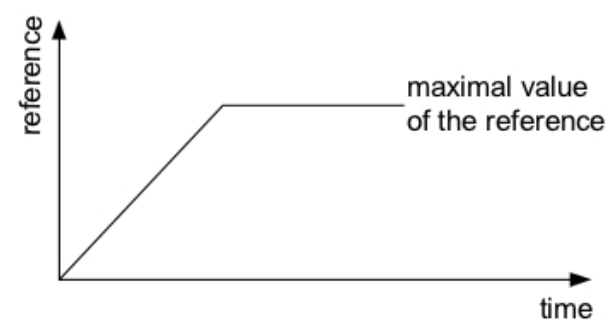

Fig 18: Reference in ramp until a wanted value.

- When the approach operation is completed, the grasping (picking) operation is now realized. In the grasping task, a step reference input $F_{c}=5 \mu \mathrm{m}$ is applied to the actuator controlled in force, while the reference deflection of the other actuator is still left equal to $\delta_{c}=50 \mu m$ (see Fig. 19-b).

- The operation after the grasping of the object is to perform the transport of the object. To this end, the grasping force is maintained constant $\left(F_{c}=5 \mathrm{mN}\right)$ while the deflection reference is set equal to the desired final position. For instance, we choose in this application the following series of deflection reference: first $\delta_{c}=60 \mu \mathrm{m}$, then $\delta_{c}=50 \mu \mathrm{m}$ and finally $\delta_{c}=40 \mu \mathrm{m}$. Fig. 19-c shows a photography of the transport task.

- Once the object arrives at its desired location, both the force and deflection references are reset to zero $\delta_{c}=0$ and $F_{c}=0$ (see Fig. 19-d). This allows to open the microgripper and to release the manipulated wire at the final position.

The experimental results that correspond to the pickand-place task are presented in Fig. 20. This figure demonstrates that the pick-and-place task has been successfully performed. The robustness of the computed controllers has also been demonstrated thanks to these experimental results. This robustness consists in maintaining the performances although the uncertainties and the external disturbances. These results are promising for micromanipulation and microassembly applications.

\section{CONCLUSION}

This paper presented the modeling, control and automation of a piezoelectric microgripper based on two collab- 


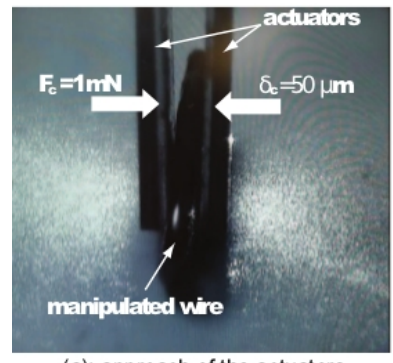

(a): approach of the actuators

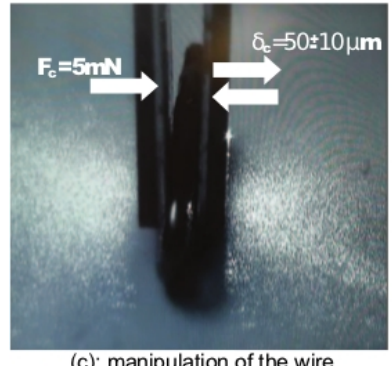

(c): manipulation of the wire

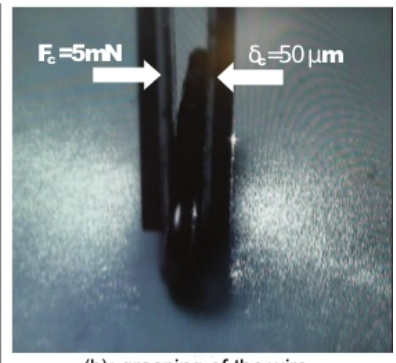

(b): grasping of the wire

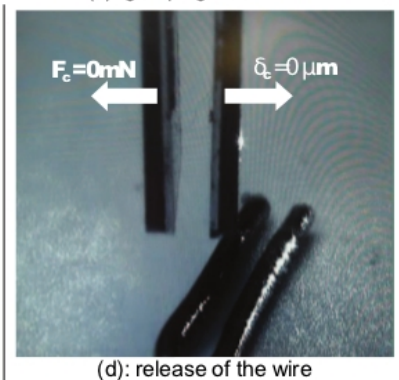

(d): release of the wire

Fig 19: a: approach of the actuators. b: grasping the manipulated wire. $\mathrm{c}$ : manipulation of the wire. $\mathrm{d}$ : release of the wire.

orative piezoelectric cantilever actuators and devoted to pick-and-place tasks in micromanipulation and microassembly applications. Both the position and force are considered during the modeling and control. It has been shown that interval techniques can be used to model uncertainties characterizing the actuators of the microgripper. The main advantage of interval modeling is the ease and natural way to bound any uncertain parameter. Afterwards, two controllers have been designed for the position and force control by using the performances inclusion theorem. The proposed approach allowed to derive robust and low order controllers. Finally, calculated controllers and the microgripper were used to perform successfully an automated pick-and-place task of small object. The experimental results validated the efficiency of the proposed approach and demonstrated its interest for the control of microgrippers used in automated micromanipulation or microassembly applications.

\section{ACKNOWLEDGMENTS}

This work has been supported by the Labex ACTION project (contract "ANR-11-LABX-01-01").

\section{REFERENCES}

[1] Y. Haddab, N. Chaillet, and A. Bourjault, A microgripper using smart piezoelectric actuators, in Proceedings of IEEE/RSJ International Conference on Intelligent Robots and Systems, Takamatsu, Japan, 2000 .
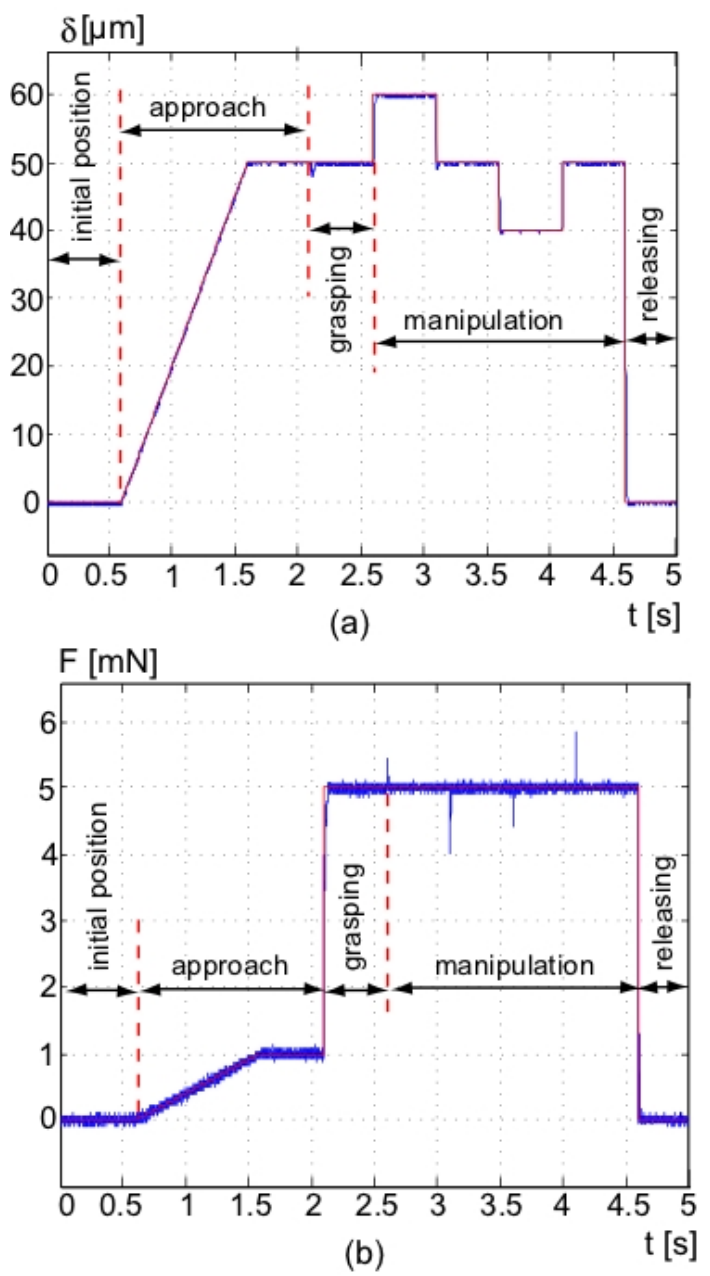

Fig 20: Experimental results of an automated pick-andplace task using a piezoelectric microgripper. a: reference input and deflection output (for the actuator controlled in deflection). b: reference input and force output (for the actuator controlled in force).

[2] J Agnus, P Nectoux, and N Chaillet, Overview of microgrippers and design of a micromanipulation station based on a mmoc microgripper, In Proceedings of the IEEE International Symposium on Computational Intelligence in Robotics and Automation (CIRA), 117-123, 2005.

[3] A. Menciassi, A. Eisinberg, G. Scalari, C. Anticoli, M. C. Carrozza, and P. Dario, Force feedback-based microinstrument for measuring tissue properties and pulse in microsurgery, IEEE International Conference on Robotics and Automation ICRA, Seoul, Korea, 2001.

[4] M Rakotondrabe and A Ivan, Development and Force/Position Control of a New Hybrid ThermoPiezoelectric microGripper dedicated to micromanipulation tasks, IEEE - Transactions on Automation Science and Engineering (T-ASE), Vol.8, Issue.4, 824- 
834, 0ctober, 2011.

[5] S. D. Eppinger and W. P. Seering, On dynamic models of robot force control, IEEE ICRA, 1986

[6] Micky Rakotondrabe, Cedric Clevy and Philippe Lutz, Complete open loop control of hysteretic, creeped and oscillating piezoelectric cantilever, IEEE - Transactions on Automation Science and Engineering (T-ASE), Vol.7(3), pp:440-450, July 2010.

[7] Micky Rakotondrabe, Cedric Clevy and Philippe Lutz, Modelling and robust position/force control of a piezoelectric microgripper, IEEE - CASE International Conference on Automation Science and Engineering, 39-44, Scottsdale AZ USA, Sept 2007.

[8] S Khadraoui, M Rakotondrabe and P Lutz, Interval Modeling and Robust Control of Piezoelectric Microactuators, IEEE - Transactions on Control Systems Technology (T-CST), 1-9, 2011.

[9] L H Keel and S P Bhattacharyya, Control system design for parametric uncertainty, International Journal of Robust and Nonlinear Control, Vol.4, 87-100, 1994.

[10] L Jaulin, M Kieffer, O Didrit and E Walter, Applied Interval Analysis, Springer, 2001.

[11] V L Kharitonov, Asymptotic stability of an equilibrium position of a family of systems of linear differential equations. Differential'nye Uravnenya, 14, 2086-2088, 1978.

[12] E Walter and L Jaulin, Guaranteed characterization of stability domains via set inversion, IEEE Transaction on Automatic Control, 1minus 0.4em39(4), 886-889, 1994.

[13] Y Smaginaa and I Brewerb, Using interval arithmetic for robust state feedback design, Systems and Control Letters, 187-194, 2002.

[14] C T Chen and M D Wang, Robust controller design for interval process systems. Computers \& Chemical, Engineering, 21, 739-750, 1997.

[15] M Rakotondrabe, Performances inclusion for stable interval systems, IEEE-ACC (American Control Conference), 4367-4372, San Francisco CA USA, JuneJuly, 2011.

[16] J Bondia, M Kieffer, E Walter, J Monreal and J PicÃš, Guaranteed tuning of PID controllers for parametric uncertain systems, IEEE CDC, 29482953, 2004.

[17] K Li and Y Zhang, Interval Model Control of Consumable Double-Electrode Gas Metal Arc Welding Process, IEEE - Transactions on Automation Science and Engineering (T-ASE), 1-14, 2010.

[18] C T Chen and M D Wang, A two-degrees-of-freedom design methodology for interval process systems, Computers and Chimical Engineering, 23, 1745$1751,2000$.

[19] J Bondia and J Pico, A geometric approach to robust performance of parametric uncertain systems,
International Journal of Robust and Nonlinear Control, vol. 13, 1271-1283, 2003.

[20] R E Moore, Interval Analysis, Prentice-Hall, Englewood Cliffs N. J., 1966.

[21] M Rakotondrabe, Y Haddab and P Lutz, Quadrilateral modeling and robust control of a nonlinear piezoelectric cantilever, IEEE - Transactions on Control Systems Technology (T-CST), Vol.17, Issue 3, pp:528-539, May 2009.

[22] Lennart Ljung, System identification toolbox user's guide, The Mathworks, Vol.10(2), October 2008.

[23] M Rakotondrabe, Y Haddab and P Lutz, Modelling and $H_{\infty}$ force control of a nonlinear piezoelectric cantilever, IEEE/RSJ - IROS, (International Conference on Intelligent Robots and Systems), 3131-3136, 2007.

[24] J L Pons, Emerging actuator technologies: a micromechatronic approach, Wiley, ISBN 0-47009197-5, 2005.

[25] M Rakotondrabe, Y Haddab and P Lutz, Nonlinear modelling and estimation of force in a piezoelectric cantilever, IEEE/ASME International Conference on Advanced Intelligent Mechatronics (AIM), 1-6, Zurich Switzerland, 2007.

[26] Jaulin L, Walter E. 1993. 'Set inversion via interval analysis for nonlinear bounded-error estimation', Automatica, 29(4), 1053-1064.

[27] Micky Rakotondrabe and Philippe Lutz, Force estimation in a piezoelectric cantilever using the inversedynamics-based UIO technique, IEEE - ICRA, (International Conference on Robotics and Automation), pp:2205-2210, Kobe Japan, May 2009.

[28] Micky Rakotondrabe, 'Combining self-sensing with an Unkown-Input-Observer to estimate the displacement, the force and the state in piezoelectric cantilevered actuator', ACC, (American Control Conference), pp.4523-4530, Washington DC USA, June 2013. 